\title{
TEORIA DAS REPRESENTAÇÕES SOCIAIS E TEORIA QUEER: TRAMAS POSSÍVEIS
}

\section{THEORY OF SOCIAL REPRESENTATIONS AND QUEER THEORY: POSSIBLE CHAMBERS}

\author{
Silvia Piedade de Moraes ${ }^{1}$ \\ José Roberto da Silva Brêtas ${ }^{2}$
}

\begin{abstract}
Resumo: Trata-se de um artigo teórico que tem por finalidade relacionar elementos da Teoria das Representações Sociais e da Teoria Queer, buscando identificar as similaridades e destacar os elementos encontrados na interseccionalidade das teorias e a potencialidade de ambas enquanto aporte teórico e metodológico na produção de conhecimento no interior da pesquisa qualitativa.
\end{abstract}

Palavras-chave: Pesquisa qualitativa; Representação social; Teoria Queer.

Abstract: It is a theoretical article whose purpose is to relate elements of the Theory of Social Representations and Queer Theory, seeking to identify the similarities and highlight the elements found in the intersectionality of theories and the potentiality of both as a theoretical and methodological contribution in the production of knowledge within the qualitative research.

Keywords: Qualitative research; Social representation; Queer Theory.

\section{Introdução}

Este artigo tem como objetivo relacionar elementos da Teoria das Representações Sociais e da Teoria Queer apontando as similaridades no campo teórico e metodológico. Destacam-se os elementos encontrados na intersecção das teorias e a potencialidade de ambas em pesquisas qualitativas.

De acordo com Denzin e Linconl (2007) a pesquisa qualitativa surge de uma atribulada história nas disciplinas humanas e fora realizada inicialmente na Sociologia pela Escola de Chicago nas décadas de 1920 e 1930 de forma a determinar sua importância na investigação de sobre a vida de grupos de pessoas, e em pouco tempo, avançou para outras áreas com Educação, Ciências Políticas, Medicina e etc.

\footnotetext{
${ }^{1}$ Doutora em Ciências pela Universidade Federal de São Paulo (Unifesp). Professora da Universidade de Guarulhos (UNG). Pesquisadora do Grupo de Estudos sobre Corporalidade e Promoção da Saúde (Gecopros), Guarulhos, São Paulo, Brasil. E-mail: silviapmoraes@ hotmail.com

${ }^{2}$ Doutor em Enfermagem pela Universidade Federal de São Paulo (Unifesp). Professor associado da Universidade Federal de São Paulo - Unifesp. Líder do Grupo de Estudos sobre Corporalidade e Promoção da Saúde (Gecopros), São Paulo, São Paulo, Brasil, E-mail: jrsbretas@gmail.com
} 
Inicialmente a pesquisa qualitativa tem a intenção de entender o outro. Nesta primeira fase no início do século XX até a Segunda Guerra Mundial, suas características estão fortemente arraigadas na Antropologia e na Sociologia. Inicialmente este "outro" era um ser exótico, primitivo e de uma cultura distante da qual era o pesquisador.

Na segunda fase, houve uma formalização dos métodos qualitativos no período pós-guerra até meados de 1970. A grande preocupação nessa época foi a criação de instrumentos e suas validações com um rigor diferente da pesquisa quantitativa. Trabalhos deste tempo destacam entrevistas abertas, semiestruturadas, observação participante e análise de dados quantitativos.

No terceiro estágio, a questão interpretativa da pesquisa qualitativa ganhou destaque, já que inúmeros instrumentos de coletas de dados estavam disponíveis. A ênfase foi a de que as linhas teóricas, os instrumentos e a posição do pesquisador na pesquisa qualitativa são interpretações de interpretações. Neste estágio, Geertz (2008) com o livro "As interpretações das culturas" foi de grande influência.

Na quarta fase, em meados de 1980 certas 'verdades' ficaram abaladas com a questão interpretativa que adentrou as pesquisas científcas. A pesquisa qualitativa ganha uma conotação maior na contestação de modelos de 'verdades' e passa a assumir uma conotação de 'significados'.

Atualmente, a ideia de que os pesquisadores não podem obter diretamente as experiências vividas pelas pessoas ou grupos é compreendida como representação de representações, que em sua escrita captam nuances dos objetos que analisam.

Destaca-se que os diferentes momentos da pesquisa qualitativa não foram superados pelas fases seguintes e ainda há modelos de cada um deles no seio das pesquisas científicas qualitativas.

Denzin e Linconl (2007, p. 17) afirmam que

[...] a pesquisa qualitativa é uma atividade situada que localiza o observador no mundo. Consiste em um conjunto de práticas materiais e interpretativas que dão visibilidade ao mundo. Essas práticas transformam o mundo em uma série de representações, incluindo as notas de campo, as entrevistas, as conversas, as fotografias, as gravações e os lembretes. Nesse nível, a pesquisa qualitativa envolve uma abordagem naturalista, interpretativa para o mundo, o que significa que seus pesquisadores estudam as coisas em seus cenários naturais, tentando entender, ou interpretar, os fenômenos em termos dos significados que as pessoas a ele confere.

De acordo com Minayo (1999) a teoria é um conjunto de princípios e conceitos inter-relacionados que servem para organizar e compreender um dado objeto de estudo, assim, uma teoria consiste na possibilidade de explicar as dimensões do objeto de 
investigação e seus fenômenos. A trama de uma teoria está totalmente envolta em conceitos e esses são, segundo Minayo (1999) unidades de significação que apontam o ponto de vista, o ângulo e os aspectos do objeto estudado. Os conceitos expressam a própria condição subjetiva em que foram estabelecidos determinando a não neutralidade e a interpretação de um objeto.

As perspectivas teóricas de acordo com Butler (2016, p. 23) “[...] emergem como parte de um processo histórico, como parte de um embate constante acerca de como pensar a respeito de temas básicos [...] todos eles possuindo uma história".

Uma das questões crescentes no campo das ciências é a exploração do potencial criativo que a pesquisa qualitativa permite na agregação de elementos teóricos, coleta e análise de dados. Após tornar-se determinante na Escola de Chicago nos anos de 1920 a pesquisa qualitativa se propagou em outras disciplinas, para além da Sociologia. Denzil e Lincoln (2007, p. 16) afirmam que "a pesquisa qualitativa é em si mesma um campo de investigação [...] em torno do termo 'pesquisa qualitativa', encontra-se uma família interligada e complexa de termos, conceitos e suposições".

Se a pesquisa fornece um espaço criativo ao pesquisador, ela oferece também uma forma de ver o objeto estudado a partir da localização do pesquisador, que por meio de práticas interpretativas, dão visibilidade ao objeto no mundo. Assim, o pesquisador tornase um bricouler, alguém que produz do conjunto de práticas interpretativas à luz das teorias, uma bricolage dos elementos que encontra no objeto estudado (DENZIL; LINCOLN, 2007). Nesse sentido, Geertz (2008, p.4) destaca que "[...] o ecletismo é uma autofrustração, não porque haja somente uma direção a percorrer com proveito, mas porque há muitas: é necessário escolher”.

Essa capacidade de produção de práticas interpretativas que a pesquisa qualitativa permite, ao contrário das resistências que existem sobre a cientificidade da mesma, garante que um mesmo objeto de estudo seja explorado em seu mundo social em inúmeras dimensões, incluindo o tempo e o contexto. Christians (2007, p. 153) chamou esse potencial da pesquisa qualitativa de suficiência interpretativa que "entende-se acompanhar com seriedade vidas repletas de múltiplas interpretações e embasadas na complexidade cultural".

Nesse artigo, o potencial metodológico da Teoria das Representações Sociais e da Teoria Queer é destacado em seus principais pontos interseccionais e a divisão entre o campo teórico e metodológico é apresentado de forma separada para facilitar a compreensão de seus elementos. 
As metodologias são caminhos instrumentais para abordar uma dada realidade. Nelas estão incluídas as técnicas e as concepções teóricas, além da possibilidade criativa e de articulação do pesquisador diante da exploração de seu objeto de estudo. Segundo Minayo (2001) as metodologias de pesquisa qualitativas são entendidas como aquelas capazes de incorporar a questão do significado e intencionalidade como inerentes aos atos, às relações e às estruturas sociais, sendo esta última tomada tanto no seu advento, quanto na sua transformação como construções humanas significativas.

A metodologia envolve a concepção teórica, os instrumentos de coleta, análise e tratamento das informações. Esse conjunto definido em torno de linhas teóricas que a sustentam dão rigor ao processo. Para Spink (1995, p. 128) é preciso superar a falsa dicotomia entre os métodos qualitativos e quantitativos e afirma que "[...] não é a verdade intrínseca de nossos instrumentos que define o rigor e sim a compreensão dos limites e possibilidades". Assim, a rigorosidade da pesquisa científica não tem sido impedimento para que o potencial criativo do pesquisador possa realizar verdadeiras bricolagens na produção de conhecimento teórico e metodológico (NEIRA; LIPPI, 2012).

Essa articulação e criação das quais o pesquisador é sujeito fundamental, funciona para assegurar o movimento na produção de sentidos, significados, mentalidades e história.

Nesse sentido, esse artigo apresenta as principais características encontradas na interseccionalidade da Teoria das Representações Sociais com a Teoria Queer enquanto aporte teórico e metodológico na produção de conhecimento no interior da pesquisa qualitativa.

\section{Intersecções sobre a origem das teorias}

A Teoria das Representações Sociais surgiu na década de 1960 e teve seu apogeu após vinte anos de latência. Ressurge na década de 1980 no seio de movimentos identitários, sobretudo, a partir de questões como 'o que é ser...?' (JODELET, 1993; ARRUDA, 2002; SILVA, 2015).

Serge Moscovici, o criador da Teoria das Representações Sociais, buscou em Émile Durkheim um primeiro abrigo conceitual para fazer objeção ao individualismo da Psicologia Social de sua época, particularmente a Americana. Utilizou o conceito de Representações Coletivas que se entendia por conhecimentos inerentes à sociedade (fenômenos como a religião, os mitos e outros) que com o passar do tempo acabavam 
fazendo parte da vida cotidiana das pessoas. Porém, apesar do reconhecimento de Moscovici de que a noção de Durkheim sobre Representações Coletivas trazia a possibilidade de compreensão das uniformidades e regularidades do pensamento social, este passa a considerá-la insuficiente para dar conta da diversidade, do fato de que nas sociedades atuais coexiste uma grande pluralidade de entendimentos e modos de organização do pensamento. Desta forma, Moscovici passa a se ocupar de representações que não são as coletivas propostas por Durkheim, mas interessa-se em compreender as representações do universo interior presentes nos indivíduos cujas características nos autorizam a chamá-las também de sociais.

Moscovici viveu em um tempo de instabilidades e relatividades nas ciências. Indagou como o conhecimento científico se transforma em comum e, portanto, como essas ideias tornam-se Representações Sociais (MARKOVÁ, 2006). Na contramão do pensamento iluminista, Moscovici colocou o senso comum num patamar semelhante ao do pensamento científico. Os saberes populares, o conhecimento do cotidiano e seus sujeitos não representam a irracionalidade, e sim, saberes reorganizados pela sua vida cotidiana, rompendo com as dualidades razão/emoção, senso comum/ciência, sujeito/objeto (ARRUDA, 2002).

Nas palavras de Moscovici (2009, p. 45) em uma sociedade pensante “[...] pessoas e grupos, longe de serem receptores passivos, pensam por si mesmos, produzem e comunicam incessantemente suas próprias e específicas representações e soluções às questões que eles mesmos colocam”. Como síntese da teoria, Oliveira (2004, p. 181) afirma que a Teoria das Representações Sociais "preocupou-se em compreender como o tripé grupos/atos/ideias constitui e transforma a sociedade".

De acordo com Miskolci (2015), o queer tanto em termos político como teórico, surgiu das inúmeras críticas à ordem sexual dos movimentos sociais emergentes na década de 1960, como dos movimentos pelos direitos civis de negros do Sul dos EUA, do ideário produzido pela segunda onda do movimento feminista e do movimento homossexual. A definição de um estatuto teórico para o queer se deu a partir de elementos dispersos advindos dos movimentos sociais organizados, dos primeiros estudos sobre os guetos e a partir de obras literárias e científicas da França, Estados Unidos e Brasil. Sua cristalização política e teórica ocorre em meados de 1980, tendo como conjuntura as especulações sobre a AIDS e os denominados na época como "grupos de risco".

Surgidos na mesma década e em conjunturas diferentes, ambas as teorias ganham forma e força no período de indagações sobre os paradigmas científicos existentes, cujas 
ideias são consideradas como essências e verdades consideradas como absolutas. Na década de 1980 quando a Teoria das Representações Sociais ressurge e a Teoria Queer se cristaliza, as realidades concretas começam a ser mais valorizadas, sobretudo, dando maior visibilidade à vida nos guetos, aos movimentos de contracultura, ao multiculturalismo e todas as suas dissidências com destaque para o estudo sobre as identidades e suas interseccionalidades ${ }^{3}$.

Borges (2014) realizou uma análise interseccional entre dois campos de conhecimento nas quais destacou seus principais aspectos de similaridade. Recontando a história da Psicologia Social e da Teoria Queer encontrou elementos necessários no contexto histórico pautados em três grandes formas de interpretar seu surgimento - a ruptura, a aproximação e a emergência.

Na ruptura, a Psicologia Social se distancia da Psicologia Positivista e a Teoria Queer do pensamento Feminista Crítico. Na aproximação, a Psicologia Social se aproxima da Sociologia e a Teoria Queer das demandas dos movimentos LGBTTQI (Lésbicas, Gays, Bissexuais, Travestis, Transgêneros, Queer e Intersexuais). A emergência é definida por uma nova forma de conceber os sujeitos e seus processos de socialização e subjetivação, destacando papel central em suas construções identitárias, dos discursos e do seu lugar no mundo. Nesse sentido, tanto uma como a outra consideram o sujeito envolto em tramas cognitivas, afetivas e comportamentais.

Nesse estudo, destacamos os elementos pertinentes às teorias das Representações Sociais e Teoria Queer apontando a origem, o campo teórico e metodológico. Em cada um desses campos elencamos características na quais suas funcionalidades operam como produtor e produto de seu corpus científico.

\section{Intersecções sobre o campo teórico}

Uma das principais relações existentes entre a Teoria Queer e a Teoria das Representações Sociais está na forma como consideram a construção das narrativas. Em ambas o discurso é um aparato de poder que envolve os conhecimentos científicos e sua

\footnotetext{
${ }^{3}$ Interseccionalidade- designa a interdependência das relações de poder de raça, classe e sexo e foi criado e usado pela primeira vez pela jurista afro-americana Kimberlé W. Crenshaw em 1989 no texto "Dermaginalizing the interseccion of race and sex: a black feminist critique of discrimation doctrine, feminist theory antiracist politics" (HIRATA, 2014). Atualmente houve uma nítida ampliação analítica do termo sendo cada vez mais utilizada, sobretudo em estudos sobre categorias identitárias que não podem ser analisadas de forma independente ou essencializadas.
} 
disseminação no tecido social. Entrelaçados às experiências individuais, sentidas e experenciadas pelos sujeitos, as apreensões estão sobre o "corpus discursivo social" e os saberes que possui.

Há nas duas teorias uma posição híbrida marcada pelas movimentações históricoculturais e contextuais. Suas teias de formação valorizam a complexidade entre os conhecimentos socialmente acumulados e os saberes individuais. Destaca-se o caráter político do conhecimento e de sua elaboração nos diferentes grupos sociais.

Em ambas as teorias, os grupos majoritariamente por onde circulam suas principais ideias e conceitos são de militantes e acadêmicos, que pouco a pouco vão disseminando nas entranhas de todo o tecido social e nas diversas modalidades de agrupamentos, uma variedade imensa de interpretações da realidade. Como Borges (2014) afirma, a militância e a academia nem sempre compartilham da mesma lógica, mas os campos de conhecimento diferenciados acabam por enriquecer um e outro.

Além disso, a Teoria das Representações Sociais considera que o lugar de onde se fala é primordial para entender a própria lógica discursiva. Assim, tratar da Representação Social da sexualidade em um grupo ativista LGBTTQI não será o mesmo que em um grupo constituído por religiosos. Para a Teoria Queer, o lugar de onde se fala também importa, já que as experiências do ser e estar são diferentes para cada indivíduo ou grupo.

Ambas as teorias consideram a transitoriedade dos discursos. Mesmo que um determinado elemento discursivo se mantenha inalterado, o próprio núcleo do discurso se movimenta, de forma que ora é centro e ora entorno.

A Teoria Queer emerge no seio do pensamento pós-estruturalista e a Teoria das Representações Sociais na ruptura com o positivismo, uma característica entre elas é fundante - a transitoriedade do certo e errado, ou seja, as teorias têm como preocupação não conceber o que é correto ou errôneo, mas discutir analiticamente como a ideia da verdade se forma: A partir de quê? Como? Onde? Para quem a verdade é verdade? (ARRUDA, 2002; GAMSOM, 2007; MISKOLCI, 2015).

$\mathrm{Na}$ conjuntura científica em que a Teoria das Representações Sociais ressurge (JODELET, 1993) e a Teoria Queer se cristaliza (MISKOLCI, 2009; MISKOLCI, 2015) as variações discursivas dos diferentes grupos e sujeitos já eram colocadas em xeque, tanto nos elementos de sua constituição quanto na manutenção do próprio discurso. Isso se deve é claro às mudanças ocorridas, sobretudo, no aparato das psicologias e na consolidação de um novo campo como a Psicologia Social - lugar de nascimento da Teoria das Representações Sociais (BORGES, 2014). As mudanças científicas sobre a 
relação existente entre o sujeito e o objeto de pesquisa não é mais uma relação linear de forma que passam a ser olhados como uma relação de constante afetação e "refazimento". A estabilidade de certas noções é mergulhada numa crise epistemológica (BORGES, 2014) o que contribuiu fortemente à crítica sobre a manutenção das normatividades, ponto central da Teoria Queer.

A ruptura na estrutura da Psicologia e sua aproximação dos Estudos Culturais, da Sociologia e da Antropologia oportunizaram a vazão ao campo da Psicologia como aquela que está imersa nas estruturas sociais e, portanto, na sua maleabilidade. Assim se fundamenta cada vez mais uma crítica ao essencialismo (BORGES, 2014; GAMSOM, 2007).

Nesse sentido, tanto a Teoria Queer quanto a Teoria das Representações Sociais propõe novas leituras às demandas sociais e fatos políticos, assim como as noções arraigadas no senso comum e no conhecimento científico (BORGES, 2014).

Ambas as teorias se valem não somente o que se discursa, mas também de quem é o discurso. Essa questão já fora amplamente discutida por Foucault $(2004,2009)$ na dissecação dos discursos como dispositivo de poder. Todo o corpus discursivo é analisado a partir das ideias fundantes e do que se funde, tanto quanto da legitimidade dada ao interlocutor.

Tanto a Teoria Queer quanto a Teoria das Representações Sociais tratam do campo das construções sociais e coletivas, mesclam o que é considerado senso comum e científico e analisam representações de grupos e indivíduos. Além disso, cada uma dessas categorias é estrutura e estruturante de uma variedade de campos de saberes, métodos, áreas de estudo, opiniões midiáticas, pontos de vista e etc.

Ambas têm caráter político, visto que desafiam pressupostos normativos que desestabilizam discursos sociais elucidando que determinados grupos fazem circular "suas verdades" em direções e movimentos constantes.

Os modelos de conhecimento, as formas do conhecimento da "verdade", como elas se constituem e por onde circulam são formas de reconhecimento nas teorias que não produzem hierarquias de saberes a partir de uma ciência "reconhecida", mas atuam como resistência em favor da ideia de que há muitas ciências.

Nesse sentido, a ideia de contexto é fundamental. Segundo Spink (1995) a noção de contexto deve ser vista também em uma perspectiva temporal e social. As Representações Sociais e os saberes trarão estruturas locais e temporais engendradas em seus discursos já que estas são frutos de complexas interações. Tanto na Teoria das 
Representações Sociais quanto na Teoria Queer, as direções do conhecimento não são priorizados em nenhuma ordem e com nenhuma intensidade pré-definida. Assim, não se nega o caráter ideológico de cada uma delas, mas provoca-se uma analítica sobre sua formação.

Em ambas, seu caráter de reflexividade traz à tona a complexa teia de valores nas quais os conhecimentos estão imersos. A reflexão também tem relação com os conhecimentos situados que tratam os saberes localizados em seus contextos de produção. Se o conhecimento não é algo dado a priori, é sim construído a partir da emancipação de alguns sujeitos e suas formas de pensar.

Tanto na Teoria Queer quanto na Teoria das Representações Sociais o sujeito tem local privilegiado. Nos dois campos teóricos a ideia de sujeito não é universal, prédefinido ou generalizado (JODELET, 1993; GAMSOM, 2007). Há cada vez mais a possibilidade de localizar o sujeito em suas múltiplas identidades, interseccionalidades e pelos grupos aos quais participa, ou seja, os sujeitos são realocados ou reposicionados a partir da analítica que deseja realizar.

A Teoria Queer e a Teoria das Representações Sociais são teorias que não dizem respeito a uma área de conhecimento específica, mas uma forma de pensar a desconstrução de verdades arraigadas ao aparato discursivo tendo uma analítica sócioconstrucionista (GAMSOM, 2007; REIS, 2014).

As realidades são efeitos discursivos, produtos de seus sujeitos e das suas formas de concebê-los. Nas teorias, o sujeito ocupa posições ou categorias (assumidas ou designadas) e pelo lugar em que estão situam seu corpus discursivo.

Nas duas teorias é possível perceber narrativas dominantes e noções hegemônicas. Desta forma, as teorias são também formas políticas de organização do pensamento social em que os significados e ideias predominantes passam por diferentes temporalidades e densidades. O contexto não é visto como homogêneo. É considerado político, repleto de tensões, conflitos e dissidências. O contexto não está isento de posições contraditórias, não há nada de fixo no lugar, no tempo ou no sujeito.

Para Halperin (1995 apud BORGES, 2014, p. 285) “[...] O queer é uma posicionalidade [...]" e se o contexto em toda sua ampla conceituação denota a posição em que o objeto de pesquisa está imerso em dada realidade, então a Representação Social também é "posição".

Ambas as teorias atuam em campos de tensão. Assim como a Teoria das Representações Sociais, na Teoria Queer o maior ponto de tensão é justamente o cerne 
de sua preocupação - a relação entre o que é considerado universal e o que é particular, $o$ que é do coletivo e o que é do individual.

Nas duas teorias há o pressuposto de que o caráter dos discursos, das representações e das ideias será sempre limitado. Mesmo assim, seu caráter de historicidade não diminui seu rigor científico. Outro ponto fundamental é de que os sujeitos estão imersos em outras inúmeras categorias como raça, etnia e classe social e que, portanto, suas representações e discursos recebem impactos de todas as suas interseccionalidades.

Embora o ponto central da reflexão da Teoria das Representações Sociais não seja diretamente o poder como na Teoria Queer, este não está ausente na percepção sobre como as representações se formam a partir das hierarquizações das verdades dos universos reificados ${ }^{4}$ e da pressão sobre a inferência ${ }^{5}$ e, portanto, caracteriza uma analítica do poder. Isso quer dizer que a comunicação nas duas teorias em forma, conteúdo e interlocutores tem como características sua fluidez e intensidade (SILVA, 2015).

Ambas as teorias afirmam que os saberes do cotidiano organizam a conduta dos indivíduos e lhes dão sentido; é uma forma de apreensão da realidade que mantém seus significados afetivos subjetivos. Encontra-se nesse ponto os elementos de performatividade presentes nas teorias. A performatividade, como afirma Butler e Louters (1998) não é uma cópia, é uma interpretação da realidade, cujas expressões únicas do sujeito, como a afetividade, são subjetivamente incorporadas ao sentido que dá a essa realidade.

\section{Intersecções sobre o campo metodológico}

Tanto a Teoria Queer quanto a Teoria das Representações Sociais podem ser utilizadas também como metodologia de pesquisa. Como já apontamos anteriormente, a metodologia envolve a concepção teórica, os instrumentos de coleta, análise e tratamento das informações da pesquisa.

Ao desvelar as Representações Sociais de um determinado objeto de investigação, vem à tona não só a constituição histórica do objeto, mas as ideias, opiniões, mitos e tabus que apontam a sobrevivência de inúmeros discursos e os conteúdos afetivos arraigados à sua representação. Na Teoria Queer como campo metodológico, a proposta é o de “[...]

\footnotetext{
${ }^{4} \mathrm{O}$ campo do conhecimento científico.

${ }^{5}$ A influência que os sujeitos recebem sobre uma visão de mundo ou ideia.
} 
enfocar, também, os variados processos de produção de conhecimento" (REIS, 2014, p. 245). Nesse sentido, ambas as teorias congregam elementos da construção da subjetividade dos objetos investigados.

De acordo com Gamsom (2007) há muitas perspectivas para o Queer e uma delas pode ser usada para uma análise da sociedade. Cada vez mais a perspectiva da Teoria Queer tem tratado da circulação dos discursos na sociedade não somente tendo a sexualidade como objeto, mas nas inúmeras configurações identitárias e sua imersão analítica para questionar o ideal de um "mundo pronto", discursivo, político-cultural e sem ambiguidades.

Tanto quanto a Teoria das Representações Sociais, a Teoria Queer como campo metodológico "[...] tem sido discutida e apresentada como aquele que subverte padrões rígidos relacionados ao fazer científico" (REIS, 2014, p. 245). Proposta similar ocorreu nos anos de 1980 com o ressurgimento da Teoria das Representações Sociais. Tanto uma quanto outra estão abertas para as mais variadas possibilidades de bricolagem científica e estruturas investigativas. De acordo com Jodelet (1993) na Teoria das Representações Sociais há inúmeras formas de conceber a investigação de seus objetos de pesquisa, não se tratando de uma forma fechada e rígida.

Outra importante similaridade de campo metodológico reside na proposta de desconstrução do objeto pesquisado, desnaturalizando concepções fixas, de forma a explicar que o objeto pesquisado está imerso em uma história cultural, o modo pela qual foi produzido e os impactos de sua produção (REIS, 2014; JODELET, 1993). Tanto em uma quanto na outra, os processos de classificação, organização, hierarquização e normalização são maleáveis, transitórios e não traduzidos em realidades universais (JODELET, 1993; REIS, 2014; MISKOLCI, 2015).

Por tratarem de interpretações da realidade, as teorias enfocam a posição do sujeito (JODELET, 1993; GAMSOM, 2007) e tem o ímpeto de questionar não somente a posição, mas a construção da posicionalidade na realidade estudada. Assim, ambas lidam em conhecer também a produção de tal conhecimento ou realidade enquanto processo cognitivo, afetivo e social.

Como já visto, as teorias têm ampla capacidade de dialogarem com outras áreas do conhecimento (JODELET, 1993; GAMSOM, 2007; REIS, 2014). Esse caráter transdisciplinar enfatiza a ideia de que em ambas, os próprios conteúdos cognitivos, afetivos, morais, sociais são criados e recriados dentro da cultura da vida cotidiana, que por sua vez não está dividida em campos dispersos, pois os sujeitos afetam e são afetados 
a todo instante pela circulação de novas representações e modalidades do pensamento social e da vida prática.

$\mathrm{Na}$ Teoria das Representações Sociais é preciso considerar que as ideias circulantes se fortalecem como hegemônicas e destacam certos aspectos da Representação Social de um grupo no fenômeno que Moscovici (1978) denominou como pressão à inferência, ou seja, quando um grupo tem maior potencial para determinar ideias dominantes.

A Teoria Queer e sua construção no seio do pós-estruturalismo considera que a hegemonia de uma linguagem e/ou discurso fortalece certas ideias e produz sujeitos reconhecidos ou abjetos. Esse fenômeno Jacques Derrida (1989) chamou de citacionalidade (DIAZ, 2013). Ambas têm a repetibilidade para reforçar uma ideia ou produzir uma identidade ou performance.

Como campo metodológico, as análises dos objetos de pesquisa desvelam sua própria historicidade, revelando, inclusive, a sobrevivência de discursos e as estruturas de poder que o engendram. Além do mais, as teorias tratam de analisar a comunicabilidade, seja pelo fenômeno discursivo, midiático, factual, corporal e de outros dispositivos.

Tanto a Teoria Queer quanto a Teoria das Representações Sociais na sua analítica, observam como os discursos se fundamentam e em quais referências históricas estão arraigadas, podendo tratar-se da genealogia de determinada ideia ou conhecimento. Assim, se para ambas o discurso é uma construção coletiva, também é o efeito dessa construção, que no âmbito negativo produz estigmas e a própria abjeção de corpos, sujeitos e conhecimentos.

A ideia de que nada é produzido no campo do individual, mas reproduzido, recriado e reestaebelecido por meio de efeitos como a subjetivação, é condição fundante em ambas as teorias e enfatizam suas aproximações com a ideia de alteridade. As Representações Sociais são fenômenos de grupos nas quais as ideias circulam de um para outro ganhando aspectos cada vez mais coletivos e ao mesmo tempo recriados pelo indivíduo. A Teoria Queer é marcada por um conjunto de identidades e visão de mundo na qual a diferença serve como ponto central para compreensão da inteligibilidade. É por meio da resistência aos discursos héteros e cisnormativos que se congregam o espaço criativo na luta por uma identidade legitimada pelo sujeito e reconhecida socialmente.

Como campo teórico-metodológico, as teorias têm caráter de ação política. Os resultados de muitas investigações servem como norte para práticas militantes de 
desconstrução ou reforço de inúmeros discursos que apresentam resultados consideráveis sobre as condutas de grupos e sujeitos de uma dada realidade. Ao compreender " $o$ que", "como" e "por que" pessoas e grupos pensam e agem, criam-se variadas estratégias de intervenção. O desvelar dos discursos para a Teoria das Representações Sociais e para a Teoria Queer como metodologias têm grande importância.

Na Teoria Queer e na Teoria das Representações Sociais o âmbito político da análise pode desvelar como grupos em posição social de prestígio e poder têm interesses para que determinados discursos e representações sobrevivam. Desta forma, a própria ideia de minoria pode ser interpelada como apresenta Scott (2005) - esses grupos são assim referidos em consonância à correlação de forças e capacidade de atuação em comparação ao coletivo dominante, ou seja, diz respeito não há uma quantidade numérica, mas em sua relação de poder de decisão, visibilidade de seus discursos e suas teias de empoderamento na conjuntura e, portanto, na instalação de paradigmas.

Assim, as teorias estabelecem seu caráter político porque desnaturalizam as influências dessas redes de informações e conhecimentos por onde circulam saberes e até determinada ordem para elaboração e disseminação. Toda essa movimentação é formadora de sistemas de significações e versões da realidade, que aliadas aos conteúdos afetivos individuais estabelecem a maneira como os sujeitos são e estão no mundo, além da forma de conceber e representar sua estadia.

A potência conjunta das teorias reside na possibilidade em estabelecer um processo desnaturalizante de imagens, discursos, posições, conhecimentos e sentimentos e seu potencial construcionista que considera os efeitos do coletivo e do individual ao mesmo tempo.

Essas teorias podem produzir uma gama imensa de possibilidades investigativas cada vez mais inteligíveis, justamente por valorizar como a realidade é vista e vivida por grupos e sujeitos diferentes. São campos teórico-metodológicos que legitimam a expressão e atuação de grupos e sujeitos como possibilidades de intervenção e transformação social da realidade.

Como apresentado, a pesquisa qualitativa favorece o potencial criativo do pesquisador. Nesse caso, agregar a Teoria Queer e a Teoria das Representações Sociais mostra que suas intersecções mobilizam o pesquisador a considerar seu papel produtor de uma novo campo, cujas rupturas entre teoria e metodologia são fundamentais para uma concepção integrada de pesquisa. 


\section{Considerações finais}

A pesquisa científica não está isenta de mudanças de paradigmas e criações de novos campos de conhecimento. Longe de ser estável, o conteúdo científico deve ser apresentado como transitório, como faceta de uma dada realidade mutável e historicizada.

Apresentar as imbricações existentes e possíveis entre a Teoria das Representações Sociais e da emergente Teoria Queer é procurar compreendê-las como frutos de um tempo em que as verdades são consideradas cada vez mais transitórias. O conhecimento não é mais algo que sujeitos e grupos possuem, mas fruto de sua própria elaboração e transformação.

Distante de querer encerrar a análise das intersecções entre as teorias, os elementos presentes em ambas, como a reflexividade, conhecimentos situados, historicidade, subjetividades, performatividade, ação política, alteridade, citacionalidade, contextualidade e produção discursiva presentes em seus fundamentos teóricos e metodológicos, mostram a capacidade de ambas em oferecer ao pesquisador uma nova abordagem qualitativa em relação ao objeto da pesquisa.

A simbiose das teorias revela também que tanto a Teoria Queer se vale de representações sociais, quanto a Teoria das Representações Sociais se valem da reconstrução e desconstrução de efeitos sobre discursos e sujeitos.

A aproximação existente entre as teorias desvela um campo da cientificidade em que produtor e produto atuam juntos e tem os próprios sujeitos como elemento principal de sua problematização.

\section{Referências}

ARRUDA, A. Teoria das Representações Sociais e Teorias de Gênero. Cadernos de Pesquisa, São Paulo, s.v., n.117, p. 127-147, nov. 2002.

BORGES, L. S. Feminismos, Teoria Queer e Psicologia Social Crítica: (re)contando histórias. Psicol. Soc., Belo Horizonte, v. 26, n. 2, p. 280-289, ago. 2014.

BUTLER, J.; LOURTES, M. Actos performativos y constitucióndel género: um ensayo sobre fenomenología y teoría feminista. Debate Feminista, Ciudad de México, v. 18, s.n., p. 296-314, out. 1998.

BUTLER, J. Corpos que ainda importam. In: COLLING, L. (Org.). Dissidências sexuais e de gênero. 1. ed. Salvador: EDUFBA, 2016. p. 21-42.

CHRISTIANS, C. G. A ética e a política na pesquisa qualitativa. In: DENZIN, N. K;

LINCONL, Y. S. (Orgs.). O planejamento da pesquisa qualitativa: teorias e abordagens. 2. ed. São Paulo: Artmed, 2007. p.141-158. 
DENZIN, N. K; LINCONL, Y. S. Introdução. In: DENZIN, N. K; LINCONL, Y. S. (Orgs.). O planejamento da pesquisa qualitativa: teorias e abordagens. Trad. Sandra Regina Netz. 2. ed. São Paulo: Artmed, 2007. p. 15-39.

DERRIDA, J. Firma, acontecimiento, contexto. 1.ed. Madrid: Cátedra, 1989.

DIAZ, E. B. Desconstrução e subversão - Judith Butler. Sapere Aude, Belo Horizonte, v. 4, n. 7, p. 441-464, jan./jun. 2013. Disponível em:

<http://periodicos.pucminas.br/index.php/SapereAude/article/viewFile/5543/5507>. Acesso em: 5 ago. 2017.

FOUCAULT, M. Microfísica do poder. 20. ed. São Paulo: Graal, 2004.

FOUCAULT, M. A ordem do discurso - aula inaugural no Collège de France. 19. ed. São Paulo: Loyola, 2009.

GAMSON, J. As sexualidades, a teoria queer e a pesquisa qualitativa. In: DENZIN, N K; LINCONL, Y. S. (Orgs.). O planejamento da pesquisa qualitativa: teorias e abordagens. 2. ed. São Paulo: Artmed, 2007. p. 345-361.

GEERTZ, C. A interpretação das culturas. 1. ed. Rio de Janeiro: LTC, 2008.

HIRATA, H. Gênero, classe e raça: interseccionalidades e consubstancialidade das relações sociais. Tempo soc., São Paulo, v. 26, n. 1, p. 61-73, jun. 2014.

JODELET, D. Représentations sociales: um domaine em expansion. In: JODELET, D. Les representations sociales. 3. ed. Paris: PUF, 1993. p. 1- 21.

MARKOVÁ, I. Representações Sociais: velhas e novas. In: MARKOVÁ, I. Dialogicidade e Representações Sociais: as dinâmicas da mente. 1. ed. Petrópolis: Vozes, 2006. p.169-205.

MINAYO, M. C. S. O desafio do conhecimento: pesquisa qualitativa em saúde. 8. ed. São Paulo: HUCITEC, 1999.

MINAYO, M. C. S. (Org.). Pesquisa Social: teoria, método e criatividade. 18. ed. Petrópolis: Vozes, 2001.

MISKOLCI, R. Teoria Queer: um aprendizado pelas diferenças. 2. ed. Belo Horizonte: Autêntica, 2015.

MISKOLCI, R. A Teoria Queer e a Sociologia: o desafio de uma analítica da normalização. Sociologias, Porto Alegre, s.v., n. 221, p. 150-182, jan./jul. 2009.

MOSCOVICI, S. A Representação Social da psicanálise. 1. ed. Rio de Janeiro: Zahar editores, 1978.

MOSCOVICI, S. Representações Sociais: investigações em psicologia social. 6. ed. Petrópolis: Vozes, 2009.

NEIRA, M. G.; LIPPI, B. G. Tecendo a colcha de retalhos: a bricolagem como alternativa para a pesquisa educacional. Educ. Real., Porto Alegre, v. 37, n. 2, p. 607-625, ago. 2012.

OLIVEIRA, M. S. B. S. Representações sociais e sociedades: a contribuição de Serge Moscovici. Rev. bras. Ci. Soc., São Paulo, v. 19, n. 55, p. 180-186, jun. 2004. 
REIS, C, D. O uso da metodologia queer em pesquisa no campo do currículo. In: MEYER, D. E.; PARAÍSO, M. A. (Orgs.). Metodologias de pesquisa pós-crítica em educação. 2. ed. Belo Horizonte: Mazza Edições, 2014. p. 245-262.

SCOTT, J. Gênero: uma categoria útil de análise histórica. Educação \& Realidade, Porto Alegre, v. 20, n. 2, p. 71-99, jul./dez. 1995.

SILVA, T. B.R. Representações Sociais: transformações e dissidências no movimento feminista, LGBT e transfeminismo. In: SEMINÁRIO INTERNACIONAL DE PÓSGRADUAÇÃO EM CIÊNCAIS SOCIAIS, 1, 2015, Marília. Anais... São Paulo, 2015. p. 1-13. Disponível em: < http://www.marilia.unesp.br/Home/Eventos/2015/iseminariointernacionalposgraduacaoemcienciassociais/5.-tamires-barbosa-rossi-silva.pdf>. Acesso em: 27 mai. 2016.

SPINK, M. J. Desvendando as teorias implícitas: uma metodologia de análise das representações sociais. In. JOVCHELOVITCJ, S.; GUARESCHI, P. (Orgs.). Textos em representações sociais. 4.ed. Petrópolis: Vozes, 1995. p. 117-145.

Recebido em: 21 de novembro de 2017.

Aceito em: 25 de novembro de 2018. 